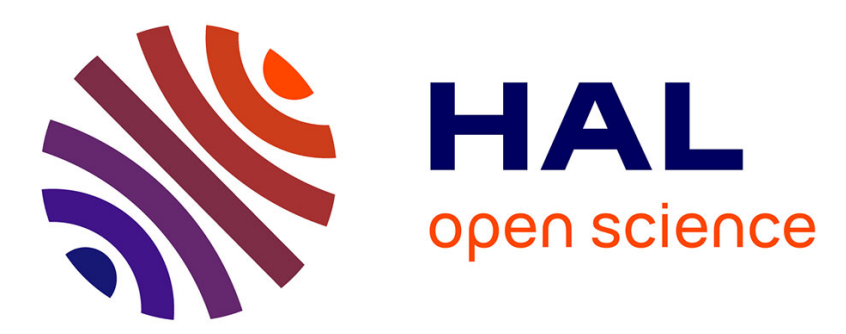

\title{
About the role of adsorption in inorganic and composite membranes
}

\author{
Anne Julbe, Martin Drobek, Andre Ayral
}

\section{To cite this version:}

Anne Julbe, Martin Drobek, Andre Ayral. About the role of adsorption in inorganic and composite membranes. Current Opinion in Chemical Engineering, 2019, 24, pp.88-97. 10.1016/j.coche.2019.03.007 . hal-02146508

\section{HAL Id: hal-02146508 \\ https://hal.umontpellier.fr/hal-02146508}

Submitted on 20 Nov 2020

HAL is a multi-disciplinary open access archive for the deposit and dissemination of scientific research documents, whether they are published or not. The documents may come from teaching and research institutions in France or abroad, or from public or private research centers.
L'archive ouverte pluridisciplinaire $\mathbf{H A L}$, est destinée au dépôt et à la diffusion de documents scientifiques de niveau recherche, publiés ou non, émanant des établissements d'enseignement et de recherche français ou étrangers, des laboratoires publics ou privés. 


\title{
About the role of adsorption in inorganic and composite membranes
}

\author{
Anne Julbe*, Martin Drobek, André Ayral \\ Institut Européen des membranes, IEM, UMR-5635 CNRS, ENSCM, Université de \\ Montpellier, Place Eugène Bataillon, 34095 Montpellier cedex 5, FRANCE
}

*Corresponding author: E-mail: anne.julbe@umontpellier.fr

Tel.: +33 467149142. Fax: +33467149119.

\begin{abstract}
Adsorption phenomena and surface-derived reactions on interfaces are fundamentally important processes in environmental chemistry, energy, catalysis or materials processing, and play a crucial role in the control of membrane performance. Adsorption of species at the surface of membrane materials has been a vast topic of investigation for decades, with both fundamental impact and direct spin-off in industry. In this minireview, the pivotal role of adsorption for both gas- and liquid- phase membrane separations is underlined with a focus on inorganic and composite membrane materials, their design strategies, transport mechanisms and associated performance. A particular attention is dedicated to fouling phenomena and emerging surface treatment methods. Finally the role of adsorption for membrane microstructure characterisation and defect detection is discussed.
\end{abstract}

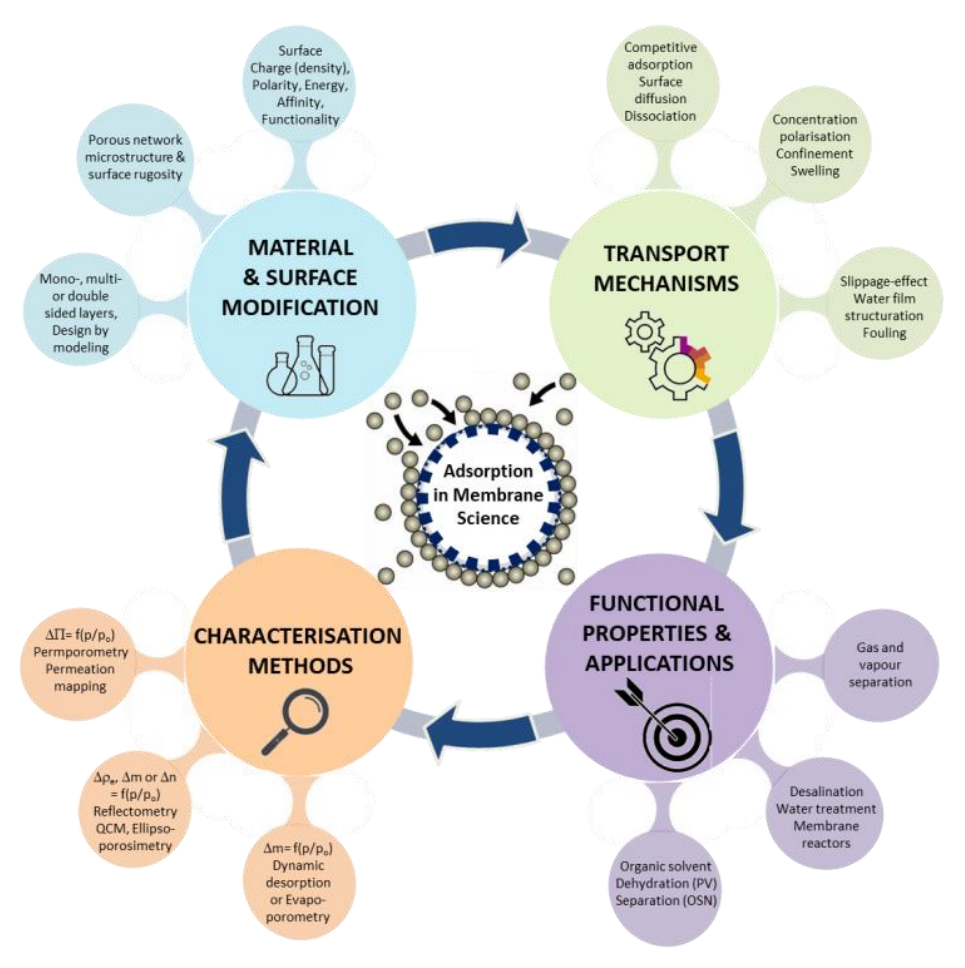




\section{Introduction}

Membranes are physical barriers allowing selective transport of chemical species such as gases, liquids, or ions. The need for continuous and efficient separation processes promises a very bright future to membranes as a versatile resource for reducing costs and environmental impacts of many industries dealing with both liquid and gas-phase separations. Membrane science is becoming increasingly mature, thanks to the strong efforts realized in both fundamental and technical aspects. The understanding of fluid-solid membrane interfaces is universally recognized as a key to harness new processes and technologies. Indeed, in most membrane applications, interfaces govern membrane performance and adsorption phenomena (either molecular physisorption or dissociative chemisorption) plays a key role. Adsorption can act as either a primary mechanism determining membrane efficiency (e.g. selectivity, permeability, reactivity, stability/durability) or a negatively impacting phenomenon (e.g. fouling) which has to be controlled and possibly avoided to guarantee performance stability.

It should be emphasized that adsorption of species at the surface of membranes always attracted strong attention in the field of membrane research. Huge progress has been made recently for a rational design of membrane surfaces and interfaces, supported by the emergence of a wide diversity of new materials and surface modification methods. Hence, the objective of this minireview is to highlight the crucial role of adsorption in membrane separation applications with a zoom on novel membrane materials and the associated transport mechanisms. The corresponding membrane performance and their fouling behavior will be illustrated, together with emerging surface treatment methods. Finally, the relevance of adsorption-coupled methods for both membrane nanostructure analysis and defects detection will be pointed out.

\subsection{Adsorption in gas phase separation}

Gas permeation mechanisms through (micro)porous membranes might include viscous flow, Knudsen diffusion, surface diffusion, multi-layer diffusion, bulk diffusion (in mixtures), and/or microporous (configurational) diffusion. The relative contributions of these mechanisms depend on process variables such as temperature, pressure, gas composition and also on membrane defects. The milestone theory of Maxwell-Stefan can be advantageously applied to model the transfer mechanisms involved in gas mixture separation [1]. Gas separation mechanisms in microporous membranes are mainly based on molecular sieving (size exclusion), difference in diffusivity, and/or competitive adsorption (e.g. strongly adsorbing components hinder the permeance of weakly adsorbing ones) (Fig.1a).

Molecular adsorption and subsequent diffusion are two major mechanisms for describing gas transport through porous membranes below $300^{\circ} \mathrm{C}$. The adsorption is usually not multilayer and often below a monolayer, so it is well described by the Langmuir adsorption model. Gas mixtures separation can be predicted from data measured for pure gases, provided that accurate sorption isotherms are available to compute the Maxwell-Stefan thermodynamic factors. The most significant theories adopted to model surface diffusion phenomenon are discussed in [2]. Gas translation (GT) competing with surface diffusion (SD) can describe light gases permeation through zeolite membranes for both single gas (e.g. $\mathrm{H}_{2}$ and $\mathrm{CO}_{2}$, fig.1b) and gas mixture diffusion [3].

Zeolites, metal organic frameworks (MOFs) or carbon molecular sieve membranes are investigated for large number of gas separation technologies involving e.g. $\mathrm{H}_{2}, \mathrm{CO}_{2}, \mathrm{~N}_{2}, \mathrm{CO}, \mathrm{CH}_{4}$, noble gases or heavy hydrocarbons (olefins/paraffins or linear/branched isomers). Due to the strong impact of competitive adsorption, membrane performance is always strongly impacted by fluctuations in the operating parameters and by the presence of impurities/contaminants in the feed gas. Comparison of membrane performance thus requires much care and efficient initial outgassing. 


\subsubsection{Zeolite membranes}

Although molecular sieving and competitive diffusivity are both governing zeolite membrane separation efficiency above $300^{\circ} \mathrm{C}$, the presence of strongly adsorbing species such as $\mathrm{CO}_{2}$, steam or other contaminants, drastically modify their performance at lower temperature (competitive adsorption). The separation of gases via zeolite membranes is quite complex, particularly in the presence of water vapour [4]. The high selectivity resulting from competitive adsorption was explored at cryogenic temperature with ultrathin highly permeable MFI (Si-rich) zeolite membrane $[5,6]$. Attractive separation factors (SF) were obtained for binary gas mixtures such as $\mathrm{O}_{2} / \mathrm{N}_{2}$ (SF=5 @67 $\mathrm{K}$ ) [5] and $\mathrm{N}_{2} / \mathrm{He}(\mathrm{SF}=62 @ 124 \mathrm{~K})$ [6]. These membranes also separate $\mathrm{CO}_{2} / \mathrm{H}_{2}$ (SF=200 @235 K) [7] or $\mathrm{CO}_{2} / \mathrm{CO}(\mathrm{SF}=21 @ 258 \mathrm{~K})[8]$.

The modification of MFI zeolite is an option to change the impact of surface adsorption (e.g. by coking, catalytic craking, or ion exchange) but it usually involves a reduction of pore sizes and permeability drops. Smaller pore size zeolites (SAPO-34, and DDR) have been considered for large scale industrial separation of $\mathrm{CO}_{2} / \mathrm{CH}_{4}$ mixtures. DDR is pure silica and provides higher steam resistance (hydrophobicity) than lower-silica polar structures [4]. When considering hydrophobisation of membrane surface, the bi-layer (or sandwich) strategy is an attractive option impacting on both competitive adsorption and membrane reactivity. The design of bi-layer MFI membranes (ZSM-5/S-1) was proposed [9] for obtaining long term steam stability at $500^{\circ} \mathrm{C}$. On the other hand, double-sided zeolite membranes deposited on both sides of the support might provide significantly higher fluxes in comparison with conventional single layer. This is particulary true when considering binary mixtures in which the more strongly adsorbed component preferentially permeates (high loading- not in the Henry regime) [10]. This double-sided strategy, limiting concentration-polarisation effects, was also found to improve the performance of MFI membranes for ethanol/water separation by pervaporation [11].

\subsubsection{Metal-Organic Framework (MOF) membranes}

Significant differences exist between the mineral structure of zeolite and the flexible hybrid structure of MOF membranes. As a direct consequence of MOF flexibility: i) molecules larger than the MOF pore aperture can adsorb and permeate through the membrane at high loading (saturation) and ii) the selectivity of large pores MOF membranes might be increased by increasing the feed pressure (pressure-related structural behaviour). Considering the complexity of MOF systems and the strong impact of operational conditions, large number of screening works was done to define the best MOF membranes for specific applications, e.g. upgrading of natural gas [12].

Recent investigations of MOF structure-performance relations [13•] revealed that MOFs with narrow pore sizes and low porosities are the best adsorbent materials for separation of $\mathrm{CO}_{2}$ from $\mathrm{H}_{2}$, whereas MOFs with large pore sizes and high porosity should be the best membrane materials for selective separation of $\mathrm{H}_{2}$. Effectively, with ZIF membranes at low temperature, relatively weak $\mathrm{H}_{2} / \mathrm{CO}_{2}$ separation factors are usually obtained, caused by preferential adsorption of $\mathrm{CO}_{2}$ blocking $\mathrm{H}_{2}$ diffusion. Working at high temperature $\left(>200^{\circ} \mathrm{C}\right)$ is an option to decrease $\mathrm{CO}_{2}$ adsorption and thus increase $\mathrm{H}_{2}$ permeation flow [14]. The design of double-layered ZIF-based membranes (i.e. ZIF-8/ZIF-9 and ZIF67/ZIF-9) could be another option [15]. The best and most remarkable performance to date $\left(\mathrm{H}_{2}\right.$ permeance of up to several thousand GPUs with $\mathrm{H}_{2} / \mathrm{CO}_{2}$ selectivity higher than 200) was obtained with ultrathin non-stacked ZIF-7 layered membranes [16]. Attractively, ZIF-8 membranes can also separate noble gas from air via a combination of molecular sieving, preferential adsorption, and diffusivity differences [17].

\subsubsection{Carbon-based membranes}

Carbon molecular sieve (CMS) membranes separate gases (e.g. for $\mathrm{CO}_{2} / \mathrm{CH}_{4}, \mathrm{H}_{2} / \mathrm{CH}_{4}, \mathrm{CO}_{2} / \mathrm{N}_{2}$ ) by both molecular sieving and selective surface adsorption/diffusion mechanisms [18]. Their huge sensitivity to both competitive adsorbing species and contaminants (e.g. steam, oxidizing species) drastically limits their applicability in real gas mixtures and imposes frequent regenerations. The type of thermosetting polymer precursor, carbonization and post-treatment/storage conditions strongly 
impact on performance. The presence of a "hyperskin" with extremely low permeance was recently detected at the outermost region of carbon hollow fibers [19]. For high pressure applications (up to 20 $\mathrm{MPa}$ ) CMS membranes are preferably supported on ceramic tubes [20].

Although graphite is hydrophobic, pyrolytic carbon membranes often contain hydrophilic groups on their pore walls when prepared from polymers containing oxygen groups and carbonized below $500^{\circ} \mathrm{C}$ [21]. In such case, water molecules are selectively transported by adsorption-diffusion mechanism, while the permeation of less adsorbable molecules is impeded. Also the hydrophilicity of twodimensional (2D) graphene and graphene oxide (GO) was vively debated. Thick graphene-layers seem to be ideal for hydrophobic applications whether single-layer graphene coatings are rather hydrophilic. The oxygen content and doping in graphene as well as the type of support strongly impact on the membrane hydrophilicity [22].

Conventional analysis of diffusive transport through graphene layers fails for such atomically thin membranes. The importance of non-covalent interactions towards $\mathrm{H}_{2}$ diffusion through graphene-based membranes has been demonstrated in a theoretical study [23•], and revealed the importance of quantum effects such as polarization and electron delocalization as key factors accounting for the energy barrier (in addition to pore size). Gas permeation can proceed via direct gas-phase interaction with the pore, or interaction via the adsorbed phase on the membrane surface (i.e. surface adsorption, surface diffusion, and pore translocation), as shown in figure 1c [24•]. The subtle interplay between relative adsorption strengths and mobilities that influence the permeation selectivities is explored in [24•] using both Maxwell-Stefan formalism (surface diffusion fluxes) and kinetic Monte Carlo simulations (to quantify the correlation effects in surface diffusion of mixtures). Neglecting slowing-down correlation effects leads to severe underestimations of the membrane permeation selectivities that favour the more strongly adsorbed species.

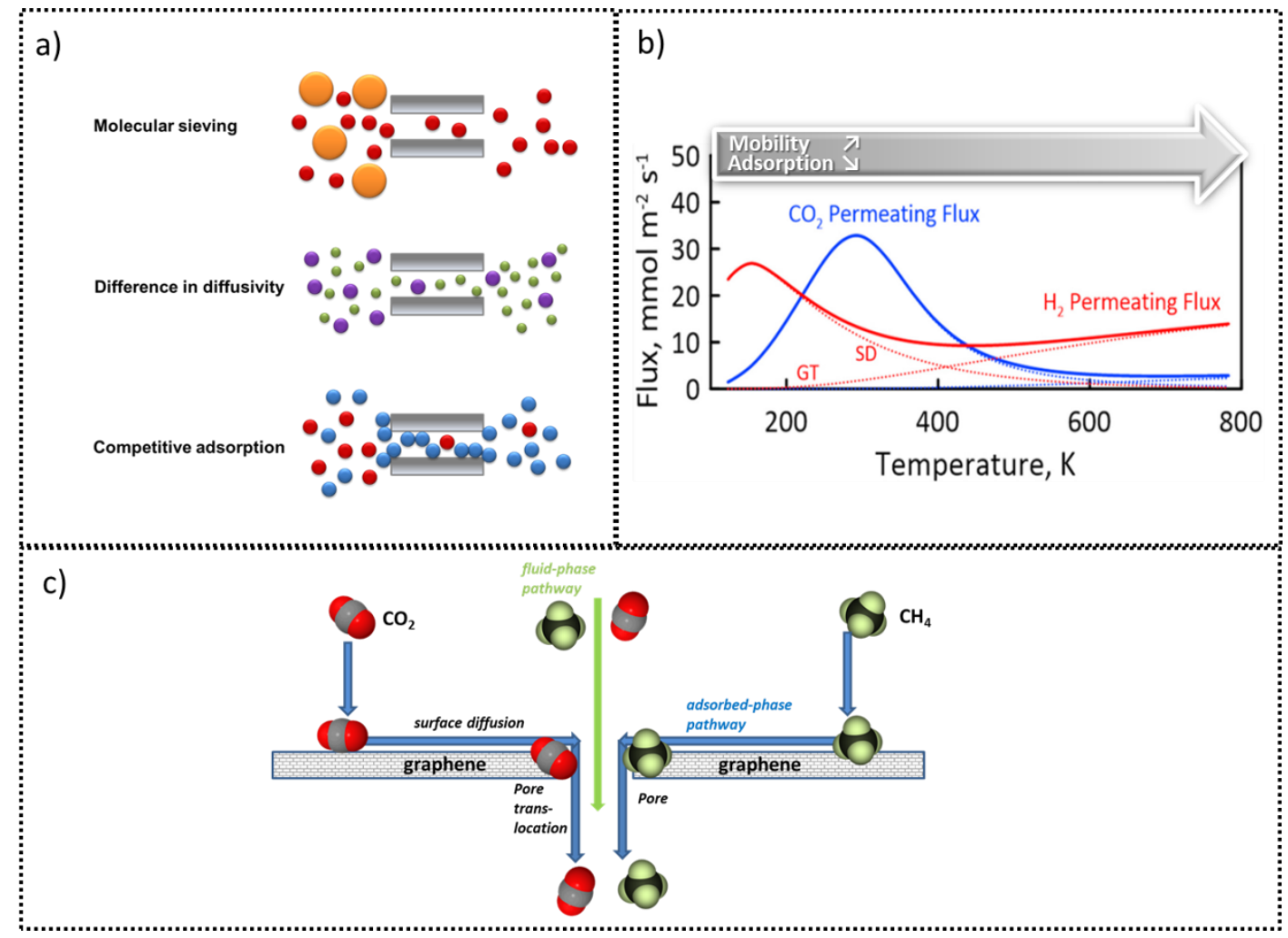

Figure 1- a) Main gas separation mechanisms in microporous membranes, b) Typical evolution vs. temperature of single gas flux through zeolite membranes-Solid lines : predicted single gas flux of $\mathrm{CO}_{2}$ and $\mathrm{H}_{2}$ through a DD3R zeolite membrane- Dotted lines : surface diffusion (SD) and gas translation (GT) contributions (adapted from [3]), c) Schematic representation of transport mechanisms though a 2D graphene membrane (adapted from [24•]). 
2.1.4. Mixed matrix membranes (MMMs) attract great attention due to their outstanding gas separation performance. They offer huge versatility by the selection of the relevant polymer matrix and the inorganic filler which is often a microporous adsorbent (e.g. zeolites, MOF clays, carbon, graphene or nanotubes...). The filler characteristics (size, morphology, particle aspect ratio, aggregation degree, pore size and size distribution, volume fraction, surface area, surface chemistry, etc.) and its batch adsorption properties (adsorption isotherm, kinetics, and conditions) are crucial for mass transfer mechanisms. The dispersion rate and volume fraction of the filler are also key factors, together with the sorption/solution-diffusion properties of the polymer and the quality of the filler/polymer interface [25]. The transport of molecules through MMM membranes typically involves the following steps: i) surface adsorption and axial diffusion through the membrane thickness, ii) radial diffusion in the polymer matrix to reach the particles surface, iii) intra-particle diffusion and adsorption on active sites of the filler. Considering that defect-free polymer/particle contact is difficult to achieve, non-ideal morphologies are usually obtained, with various types of interfacial defects such as pore blocking, interfacial voids and polymer chain stiffening, which contributions can hardly be defined and controlled [25]. Despite being promised a bright future, the design of efficient separation processes based on MMM membranes still relies to a large part on trial and error strategies. This is mainly because gas transport through such composite materials is a complicated problem in which the interface between the matrix and the dispersed filler is expected to play a key role. The available modeling approaches are often limited to empirical parameters which cannot be derived from molecular adsorption/transport coefficients. A modern computer application (Membrane Optimization Tool) for modeling gas transport processes through MMMs has been recently proposed in [26•].

2.1.5. Dense membranes (polymers, metals or ion-conducting ceramics) offer extremely high gas separation selectivity with strong impact of adsorption phenomena at the surface, as a first step. Due to their low cost, polymer membranes are largely investigated for gas separation, operating by molecular adsorption, solution-diffusion and desorption. Both gas solubility and diffusivity are tunable parameters for designing high-performance membranes [27]. Dense inorganic membranes (i.e. both metals and ceramics) are also adsorption-sensitive; although dissociative adsorption (chemisorption) is the involved mechanism for these membranes operating at high temperature.

Dense $\mathrm{Pd}$-based membranes are highly efficient for continuous $\mathrm{H}_{2}$ purification thanks to the transport mechanism shown in figure $2 \mathrm{a}$. The competitive adsorption of even small amount of $\mathrm{CO}, \mathrm{CO}_{2}$, steam or sulfur compounds (e.g. $\mathrm{H}_{2} \mathrm{~S}$ ), strongly reduces the $\mathrm{H}_{2}$ permeating flux [28•]. Coating Pd-based membrane surface with a protective film (e.g. $\mathrm{H}_{2}$ selective silica layer prepared by ALD [29]) is thus a relevant strategy which could also contribute to reduce the adsorption activation energy of $\mathrm{H}_{2}$.

Dense mixed ion- and electron-conductive (MIEC) ceramic membranes are used for either oxygen or hydrogen separation. Adsorption and surface kinetics play key roles in the transport mechanisms (fig.2b), especially for very thin membranes (i.e. below a critical thickness Lc) [30]. Surface defects are likely to act as catalytically active centers at which oxygen or hydrogen molecules dissociate. The kinetics of the surface exchange process (which also occurs reversibly at the opposite side of the membrane) are crucial for a membrane in operation and are often rate limiting. There is thus no gain by manufacturing very thin membranes unless steps are taken to improve the flux through the interfacial regions. This can be done by increasing the effective membrane surface area, either by generating irregularities (e.g. chemical etching, sand blasting, ion etching) or deposition of a high specific surface area and ideally catalytically active nanomaterial (e.g. noble metals for spillover effect or oxides) [31, 32•]. 


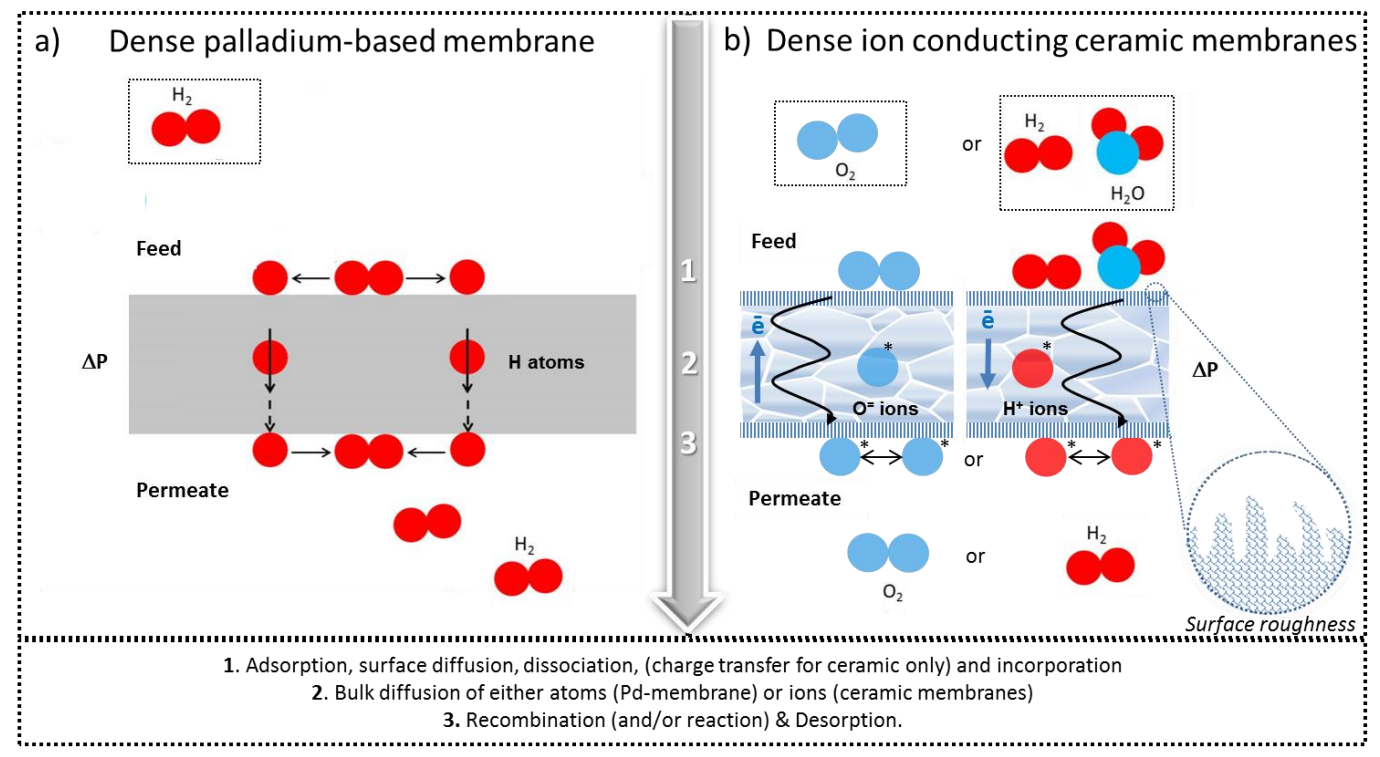

Figure 2: Different steps involved in the selective transport of hydrogen or oxygen species through: a) dense palladium-based membrane for $\mathrm{H}_{2}$ purification (adapted from [33]), or b) dense ion-conducting ceramic membranes for either $\mathrm{O}_{2}$ or $\mathrm{H}_{2}$.

\subsection{Adsorption in liquid phase separations}

Surface properties and adsorption phenomena are critical to all membrane processes in liquid phase: microfiltration (MF), ultrafiltration (UF), nanofiltration (NF), reverse and forward osmosis (RO, FO), electrodialysis (ED), bioreactors (MBR), pervaporation (PV), vapour permeation (VP) but also membrane distillation (MD) and percrystallisation (PC). Whatever the considered application (e.g. synthesis, concentration or purification of valuable molecules, wastewater treatment, desalination, organic solvents dehydration or separation,...) and concerned species (ions, molecules, colloids, cells,...) adsorption phenomena have to be controlled to optimise fluxes, selectivity and long term stability, while limiting fouling and associated issues. The complexity of interface engineering for water treatment has been recently reviewed [34].

\subsubsection{Fouling and options for surface modifications}

Fouling is a broad term that includes many types of foulant materials (e.g. organic or mineral particles or dissolved species, colloids, proteins, microbiological organisms). Strategies to combat scaling, biofouling, and non-specific organic fouling are all different. Limitation of fouling phenomena implies higher productivity, less cleaning and longer membrane life, thereby reducing operational and capital costs. The major forces contributing to the attachment of foulants on the membrane surface are dispersion and polar interaction forces [35]. When foulants are adsorbed on the membrane surface via electrostatic, hydrophobic, van der Waal, hydrogen-bonding or other interactions, they might accumulate or aggregate and form cake, gel, oil, biofilm or scaling layers. Accordingly, three different antifouling strategies can be considered [35]: i) fouling resistance (inhibiting interactions via hydration layer and/or steric hindrance effect); 2) fouling release (minimizing interaction intensity via lowsurface-energy effect); 3) fouling attack (cell inactivation and foulant oxidization via active interaction/reaction effects). A conceptual model illustrating membrane fouling and cleaning is shown in Fig.3a. Hydrophobic attraction results from van der Waals forces between molecules and the membrane material. Hydrophilic pore surfaces with highly negative charge are thus recommended for preventing adsorption of (natural) organic matter \& colloids. The recent progress in antifouling membrane surface construction has been highlighted in [36••] with a focus on bioinspired adhesion chemistry, supramolecular chemistry, mineralization chemistry, click chemistry and coupling chemistry. Substantial progress was recently achieved in interface engineering by using biomimetic concepts such as mussel-inspired chemistry, mediated by polydopamine or polyglycerol as substrate- 
independent coatings. This approach enables enormous flexibility in tuning membrane surface properties [37] and more specifically its wettability, almost independently of the native surface properties. Universal super-wetting systems were obtained by combining mussel-inspired adhesion and highly hierarchical lotus-like surface structures [38].

Insertion of inorganic nanoparticles (e.g. zwitterionic functionalized $\mathrm{MoS}_{2}$ nanosheets [39]) can also improve the hydrophilicity of common polymer membranes such as PES. On the other hand, the Grignard reaction was explored as a relevant sustainable approach to mitigate ceramic membrane fouling by surface functionalization [40]. This strategy, playing with the affinity membrane/solvent/solute, provided strong anti-fouling effect for $\mathrm{NF}$ membranes (e.g. $\mathrm{TiO}_{2}$ ), but also improved the performance of both affinity based-separations and organic solvents nanofiltration (OSN) membranes.

Scalable physical and chemical methods are available for the surface modification of existing membranes. For instance the modification of polymer membrane surface energy and functionalisation can be operated at industrial scale by non-equilibrium plasma treatment [41]. Additionnaly, ALD has

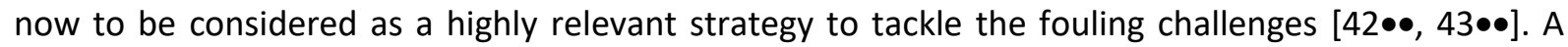
recent example of oxide interface engineering by ALD of $\mathrm{TiO}_{2}$ or $\mathrm{SnO}_{2}$ layers ( $10 \mathrm{~nm}$ thick) for crudeoil-repellent membranes was reported [44]. Molecular dynamics simulations revealed that a tightly bound hydration layer play a crucial role in protecting the surface from crude oil adhesion.

\subsubsection{New inorganic and hydrid membrane materials for liquid phase applications}

The development of new inorganic membrane materials such as MOFs, non-oxide ceramics (SiC, SiNx, $\mathrm{BN}$ ), graphene, $\mathrm{GO}$ and other nanosheet-based membranes has considerably enriched the range of accessible/tunable hydrophilicity, organophilicity and surface charge effects.

The versatility of MOF design recently led to membranes with impressive stability and performance in both water and organic media (e.g. water treatment, desalination [45], PV and OSN) [46••].

Silicon carbide $(\mathrm{SiC})$ offers decisive advantages over conventional oxide ceramic membranes in water filtration processes, namely oily water treatment. The SiC surface is naturally covered with native silicon oxide which attracts water while repelling foulants. The low zeta potential (similar to silica) and high surface hydrophilicity are responsible for high fouling resistance although a slippage effect due to a tighly bond water film on native silica could explain the high measured water fluxes.

Boron nitride is another original and promising new membrane material which is slightly polar and has a moderate surface energy $\left(40 \mathrm{~mJ} / \mathrm{m}^{2}\right)$, very similar to carbon value $\left(35 \mathrm{~mJ} / \mathrm{m}^{2}\right)$. Its high negative surface charge density might dramatically hinders ionic transport [47] and amino-functionalized BNlayered membranes revealed to be efficient for solute screening in both water and organic solvents [48]. The hydrophobicity and moderate surface energy of macroporous and mesoporous carbon membranes is well adapted to membrane distillation [49] and crystallization processes, including the continuous percrystallisation approach [50]. The unique surface properties of graphene, $\mathrm{GO}$ and other

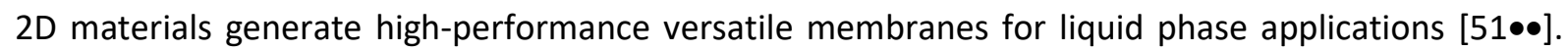
Hydrophilic GO ultrathin membranes offer ultrafast permeation of water but when designed as micrometer-thick laminates, they can also attract small ions (with hydrated radii $<4.5 \AA$ ) and provide their fast transport [52]. Contrary to water, a non-slip behavior has been evidenced for organic solvents

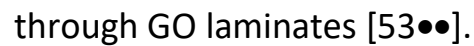

Both 2D and 3D nanomaterials are original nanofillers that contribute to enhance the development of MMM with extraordinary properties. MMM have huge potential in liquid phase applications, namely for water treatment and desalination [39], but also PV [54] and OSN [55], although there are still huge challenges to optimize MMM design for real industrial applications.

Superwetting MOF-based composite membranes for oil/water separations were obtained by integration of ZIF-8 in PAN nanofibers. They display unique wetting properties: superoleophobicity under water and superhydrophobicity under oil (Fig. 3b) and thus offer high separation efficiency (99.95\%) for oil-in-water and water-in-oil emulsions [56•]. Such membrane directly derives from the concept of adsorptive membranes described in the next paragraph. 


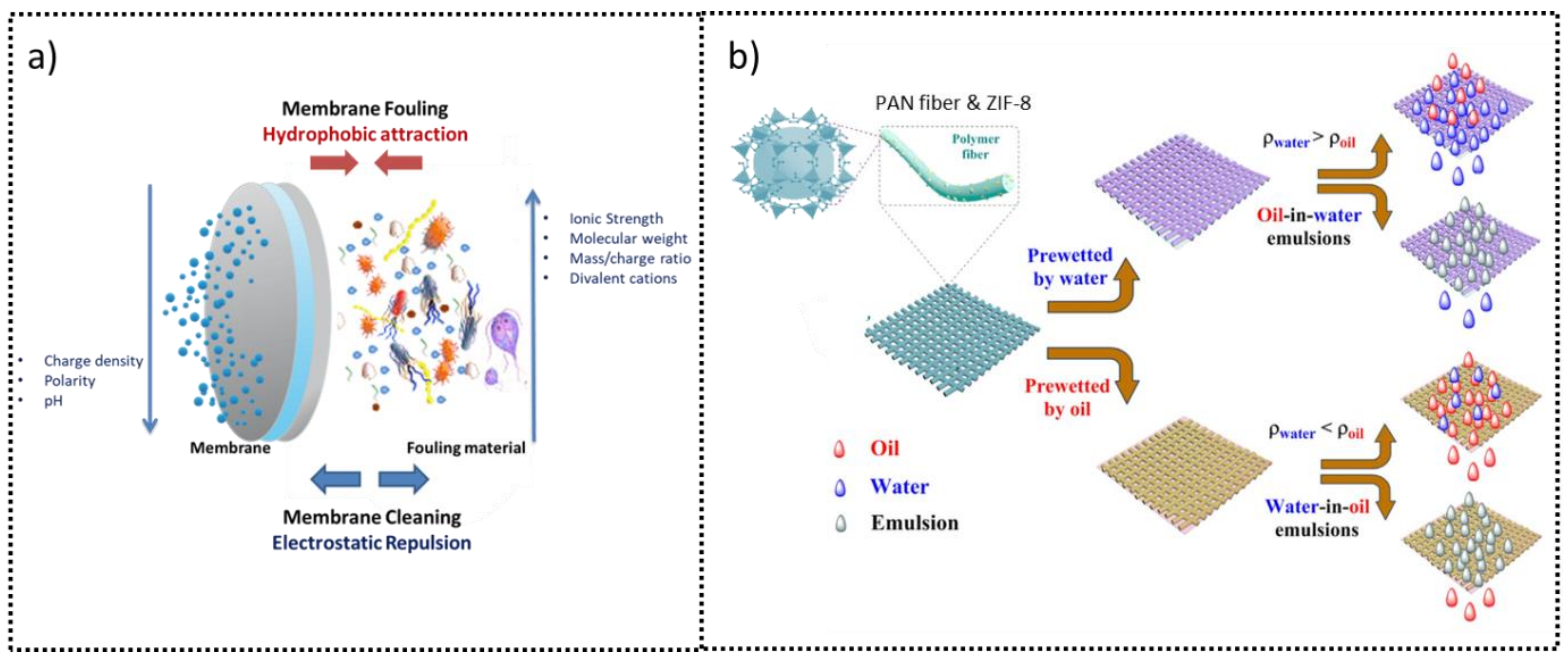

Figure 3: a) Conceptual model illustrating membrane fouling and cleaning when considering adsorption of natural organic matter, b) Schematic of the superwetting MOF-based composite membranes for continuous selective separation of oil/water mixtures and emulsions (adapted from [56•]).

2.2.3. Coupling adsorption and membrane filtration for depollution is an attractive option for waste water depollution in the presence of both a relevant adsorber (e.g. activated carbon, porous polymers, porous ceramics, MOFs...) and an efficient membrane. The drawback of this approach is related to the required adsorbent regeneration (or replacement). Adsorptive membranes are usually applied for selective metal adsorption/sequestion. They are classically prepared by functionalisation of membranes made from nanofibers such as PAN. The fiber surface can be modified with either thiocompounds for $\mathrm{Hg}^{2+}$ and $\mathrm{Cd}^{2+}$ ions adsorption or diazoresin-ethylene-diamine-tetraacetic acid layer for $\mathrm{Cu}^{2+}, \mathrm{Pb}^{2+}, \mathrm{Hg}^{2+}$ [57]. Dispersion of water-stable nanoparticles in PAN fibers is also an option: $\mathrm{Zr}$ based MOF-808 was used for $\mathrm{Cd}^{2+}$ and $\mathrm{Zn}^{2+}$ ions removal [58], activated biochar for chlortetracycline [59] and functional GO nanosheets for lithium sequestration [60].

Coupling membrane filtration with a conventional adsorption batch is also a highly relevant strategy for industry. Such adsorption-filtration-membrane (AFM) hybrid process is used for boron removal from water or for removing various micropollutants such as steroids or viruses. A hybrid RO/adsorption desalination plant (with silica gel adsorbent) was recently developed for producing irrigation and drinking water [61].

\subsubsection{Membrane bioreactors}

Extractive membrane bioreactors are developed for wastewater treatment and combine a membrane separation and the degradation of target contaminants by both an active biofilm and microorganisms in the bioreactor. The physicochemical properties of membrane surfaces on the receiving side facing the bioreactor are critical in controlling the extent and nature of the membrane-attached biofilm. An original "Janus-type" nanofibrous composite membrane with opposing wetting properties (superhydrophobic PVDF/superhydrophilic PDMS) was reported [62•] for an efficient extraction of phenol in long-term operation. The fouling-releasing fluoro-polymeric surface was found to attenuate the tendency of microbial attachment and encourage biofilm scouring.

\subsection{Adsorption for the characterisation of nanopores and defects in membranes}

Membrane science requires particular attention to defect detection methods and to the complex characterization of the microstructure of very thin supported nanoporous layers. Coupled methods based on the controlled adsorption of a probe molecule (vapor), appear as highly powerful either for 
the analysis of accessible porous network in thin membranes at room temperature or for the specific analysis of active pores and defects contributing to fluid transport (Fig. 4).

Relevant physical methods such as quartz crystal microbalance, ellipsometry or X-ray reflectometry, can be used to study the adsorption in the open porosity/free volume of the film versus relative pressure $p / p_{0}$, by measuring the mass up-take, refractive index or electronic density variations, respectively. The film thickness evolution, contraction or swelling during the sorption can also be monitored by the two latter techniques. Kinetic investigation of the penetration rate can be used to estimate both the membrane permeability and diffusivity coefficient of the selected probe [63]. This could be highly attractive for high throughput-screening of membrane materials. Desorption porosimetry [64] and evapororometry [65], both based on the measurement of weight variation during controlled vapor evaporation, are also ranked as adsorption-coupled methods.

Gas permeation measurements coupled with controlled adsorption specifically provide an analysis of active pores and defects contributing to gas transport in membranes. Permporometry is based on the controlled blocking of pores by adsorption/condensation of a vapour (e.g. ethanol, water or cyclohexane) present as a component of a gas mixture and the simultaneous measurement of the flux of a non-condensable dry gas (e.g. He) through the remaining open pores. Size distribution of active pores is derived in the mesoporous range by applying the Kelvin equation. Although this equation is non-valid in micropores, the method was applied to detect non-zeolitic pores in zeolite membranes [66]. Determination of micropore sizes in amorphous membrane materials, even semi-quatitive evaluation, is often a tricky task as far as reference t-curves are available for flat surfaces and does not account for changes in surface chemistry and confinement behaviors in the pores [67]. In addition a swelling of zeolite crystals during the adsorption step (e.g. n-hexane in MFI) might decrease the size of intercrystalline spaces/defects and alter the conclusions about membrane quality [68]. Based on the permporometry concept, a permeation-mapping (gas sniffer) can also be used [69] to visualize and locate nano-sized defects in zeolite membranes).

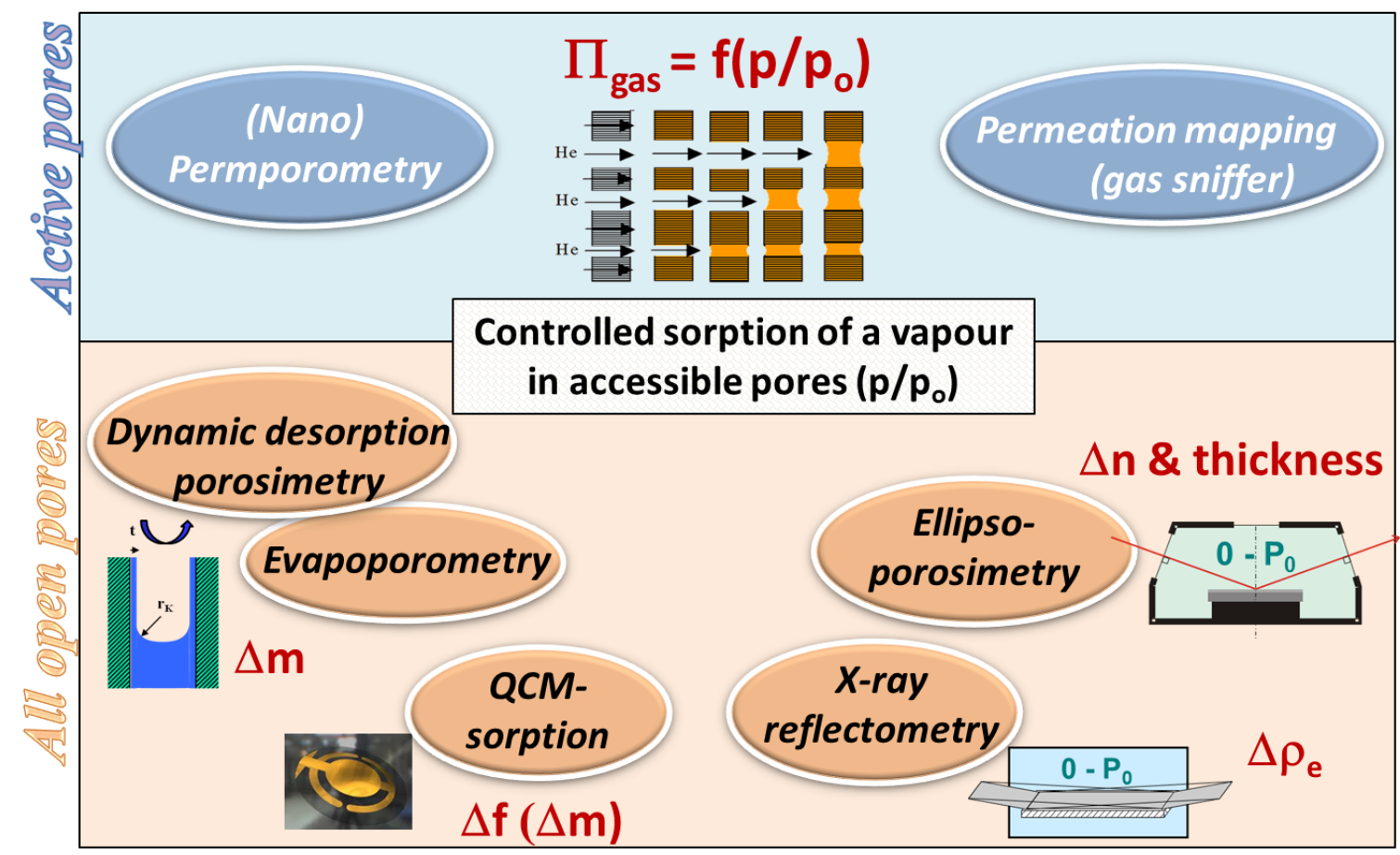

Figure 4: Main membrane characterization methods coupling the controlled sorption of a condensable phase, for analysing either all open (accessible) pores or exclusively active pores and defects contributing to fluid transport. 


\section{Conclusion and prospects}

Adsorption and associated surface phenomena are of paramount importance in governing membrane functionality and overall membrane process efficiency in gas phase and liquid phase applications. Both molecular and dissociative adsorption at the solid-fluid interfaces impact on membrane permeability, selectivity and stability. Huge progress to monitor membrane-fluid interactions has been made recently thanks to the emergence of new membrane materials with unique structure and microstructure, versatile surface modification methods and sophisticated membrane designs in synergy with increasingly powerful modeling investigations. Only few examples of up-to-date developments of inorganic and composite MMMs are illustrated in this mini-review as it is impossible to be exhaustive facing such a large diversity of results. Two-dimensional materials (e.g. graphene, GO, MOFs, $\mathrm{MoS}_{2}, \mathrm{M}$-Xene, zeolites, LDHs, COFs) are draining significant attention, aiming at the design of nanosheet membranes with outstanding performance. More sophisticated theoretical models will have important implications for the rational design of the derived complex MMM systems. Non-oxide membranes are also promised to brillant future, thanks to their surface charges and antifouling properties. Finally, very few has been done in the investigation of external stimuli (e.g. ultrasounds, piezo-electricity, magnetism, electro-stimulation) for influencing adsorption phenomena and fouling. This could lead to powerful integrated membrane systems with operando monitoring of both membrane performance and stability.

\section{The authors declare no conflict of interest.}




\section{Figure captions:}

Figure 1- a) Main gas separation mechanisms in microporous membranes, b) Typical evolution vs. temperature of single gas flux through zeolite membranes-Solid lines : predicted single gas flux of $\mathrm{CO}_{2}$ and $\mathrm{H}_{2}$ through a DD3R zeolite membrane- Dotted lines : surface diffusion (SD) and gas translation (GT) contributions (adapted from [3]), c) Schematic representation of transport mechanisms though a 2D graphene membrane (adapted from [24•]).

Figure 2: Different steps involved in the selective transport of hydrogen or oxygen species through: a) dense palladium-based membrane for $\mathrm{H}_{2}$ purification (adapted from [33]), or b) dense ion-conducting ceramic membranes for either $\mathrm{O}_{2}$ or $\mathrm{H}_{2}$.

Figure 3: a) Conceptual model illustrating membrane fouling and cleaning when considering adsorption of natural organic matter, b) Schematic of the superwetting MOF-based composite membranes for continuous selective separation of oil/water mixtures and emulsions (adapted from [56•]).

Figure 4: Main membrane characterization methods coupling the controlled sorption of a condensable phase, for analysing either all open (accessible) pores or exclusively active pores and defects contributing to fluid transport. 


\section{References:}

[1] R. Krishna, Describing the diffusion of guest molecules inside porous structures, J. Phys. Chem. C 113 (2009) 19756-19781.

[2] P.F. Lito, S.P. Cardoso, A.E. Rodrigues, C.M. Silva, Kinetic Modeling of Pure and Multicomponent Gas Permeation Through Microporous Membranes: Diffusion Mechanisms and Influence of Isotherm Type, Sep. Purif. Rev. 44 (2015) 283-307.

[3] P.F. Zito, A. Caravella, A. Brunetti, E. Drioli, G. Barbieri, Discrimination among gas translation, surface and Knudsen diffusion in permeation through zeolite membranes, J. Membrane Sci. 564 (2018) 166-173.

[4] K.C. Khulbe, T. Matsuura, C.Y. Feng and A.F. Ismail, Recent development on the effect of water/moisture on the performance of zeolite membrane and MMMs containing zeolite for gas separation, RSC Adv. 6 (2016) 42943-42961.

[5] P. Ye, D. Korelskiy, M. Grahn, J. Hedlund, Cryogenic Air Separation at Low Pressure Using MFI Membranes, J. Membrane Sci. 487 (2015) 135-140.

[6] P. Ye, M. Grahn, D. Korelskiy, J. Hedlund, Efficient Separation of $\mathrm{N}_{2}$ and He at Low Temperature Using MFI Membranes, AIChE J. 62 (2016) 2833-2842.

[7] D. Korelskiy, P. Ye, S. Fouladvand, S. Karimi, E. Sjöberg, J. Hedlund Efficient Ceramic Zeolite Membranes for $\mathrm{CO}_{2} / \mathrm{H}_{2}$ Separation, J. Mater. Chem. A 3 (2015) 12500-12506.

[8] D. Korelskiy, M. Grahn, P. Ye, M. Zhou, J. Hedlund A Study of $\mathrm{CO}_{2} / \mathrm{CO}$ Separation by sub-micron b-Oriented MFI Membranes, RSC Adv. 6 (2016) 65475-65482.

[9] H. Wang, X. Dong, Y.S. Lin, Highly stable bilayer MFI zeolite membranes for high temperature hydrogen separation, J. Membr. Sci. 450 (2014) 425-432.

[10] T.Q. Gardner, J. G. Martinek, J.L. Falconer, R.D. Noble, Enhanced flux through double-sided zeolite membranes, J. Membr. Sci. 304 (2007) 112-117.

[11] Synthesis of capillary titanosilicalite TS-1 ceramic membranes by MW-assisted hydrothermal heating for pervaporation application, Sep. Purif. Technol. 75 (2010) 249-256.

[12] Z. Qiao, Q. Xu, J. Jiang, High-throughput computational screening of metal-organic framework membranes for upgrading of natural gas, J. Membrane Sci. 551 (2018) 47-54.

-[13] G. Avci, S. Velioglu, S. Keskin, High-Throughput Screening of MOF Adsorbents and Membranes for $\mathrm{H}_{2}$ Purification and $\mathrm{CO}_{2}$ Capture. ACS Appl. Mater. Interfaces 10 (2018) 33693-33706.

Grand canonical Monte Carlo and molecular dynamics simulations are used to compute various adsorbent and membrane performance metrics of 3857 MOFs for separation of $\mathrm{CO}_{2} / \mathrm{H}_{2}$ mixtures.

[14] Y.S. Li , F.Y. Liang , H. Bux, W. Yang, J. Caro, Zeolitic imidazolate framework ZIF-7 based molecular sieve membrane for hydrogen separation, J. Membr. Sci. 354 (2010) 48-54.

[15] F. Cacho-Bailo, I. Matito-Martos, J. Perez-Carbajo, M. Etxeberría-Benavides, O. Karvan, V. Sebastián, S. Calero, C. Téllez, J. Coronas, On the molecular mechanisms for the $\mathrm{H}_{2} / \mathrm{CO}_{2}$ separation performance of zeolite imidazolate framework two-layered membranes, Chem. Sci. 8 (2017) 325-333.

[16] Y. Peng, Y. Li, Y. Ban, H. Jin, W. Jiao, X. Liu, W. Yang, Membranes. Metal-organic framework nanosheets as building blocks for molecular sieving membranes, Science 346 (2014) 1356-1359. 
[17] T. Wu, J. Lucero, M.A. Sinnwell, P.K. Thallapally, M.A. Carreon, Recovery of xenon from air over ZIF-8 membranes, Chem. Commun. 54 (2018) 8976-8979.

[18] M.-B. Hägg, X. He, Carbon Molecular Sieve Membranes for Gas Separation, Chapter: 15, The Royal Society of Chemistry, 2011, pp.162-191.

[19] O. Sanyal, S.T. Hicks, N. Bhuwania, S. Hays, M.G. Kamath, S. Karwa, R. Swaidan, W.J. Koros, Cause and effects of hyperskin features on carbon molecular sieve (CMS) membranes, J. Membr. Sci. 551 (2018) 113-122.

[20] N. Kruse, Y. Schießer, S. Kämnitz, H. Richter, I. Voigt, G. Braun, J.U. Repke, Carbon membrane gas separation of binary $\mathrm{CO}_{2}$ mixtures at high pressure, Sep. Purif. Technol. 164 (2016) 132-137.

[21] M.A. Llosa Tanco, D.A. Pacheco Tanaka, Recent Advances on Carbon Molecular Sieve Membranes (CMSMs) and Reactors, Processes 4 (2016) 29.

[22] G. Hong, Y. Han, T.M. Schutzius, Y. Wang, Y. Pan, M. Hu, J. Jie, C.S. Sharma, U. Müller, D. Poulikakos, On the Mechanism of Hydrophilicity of Graphene, Nano Lett. 16 (2016) 4447-4453.

- [23] L.A. Cunha, L.F.A. Ferrão, F.B.C. Machado, M. Pinheiro, On the importance of non-covalent interactions for porous membranes: unraveling the role of pore size, Phys. Chem. Chem. Phys. 20 (2018) 20124-20131. A theoretical study on the role of non-covalent interactions such as polarization and electron delocalization towards $\mathrm{H}_{2}$ diffusion through graphene-based membranes.

- [24] R. Krishna, The Maxwell-Stefan description of mixture permeation across nanoporous graphene membranes, Chemical Engineering Research and Design 133 (2018) 316-325.

Modeling study of surface diffusion of binary mixtures of adsorbates on 2D graphene surface, using the Maxwell-Stefan formulation.

- [25] R. Lin, B. Villacorta Hernandez, Lei Ge, Z. Zhu, Metal organic framework based mixed matrix membranes: an overview on filler/polymer interfaces, J. Mater. Chem. A, 6 (2018) $293-312$

A review that presents the recent opportunities and challenges for MOF-based MMM fabrication, emphasizing the strategies for improving the filler/matrix interface.

- [26] A. Rybak, A. Rybak, P. Sysel, Modeling of Gas Permeation through Mixed-Matrix Membranes Using Novel Computer Application MOT, Appl. Sci. 8 (2018) 1166.

First approach towards a computer application "Membrane Optimization Tool" to model the gas transport processes through the simplest mixed-matrix membranes (Maxwell model).

[27] M. Omidvar, H. Nguyen, J. Liu, H. Lin, Sorption-enhanced membrane materials for gas separation: a road less travelled, Curr. Opin. Chem. Eng. 20 (2018) 50-59.

- [28] K. Kian, C.M. Woodall, J. Wilcox, S. Liguori, Performance of Pd-Based Membranes and Effects of Various Gas Mixtures on $\mathrm{H}_{2}$ Permeation, Environments 5 (2018) 128.

Evidence the poisoning effect of steam for $\mathrm{H}_{2}$ permeation through $\mathrm{Pd}$ membranes. Adsorption of oxygen atoms occurs through $\mathrm{H}_{2} \mathrm{O}$ decomposition/recombination on the active surface of Pd.

[29] C. Yi A. Tsai, S.-Y. Tam, Hydrogen selective protective coating, 2014, US Patent T3 Scientific, US8900344B2.

[30] M.-L. Fontaine, T. Norby, Y. Larring, T. Grande, R. Bredesen, Oxygen and Hydrogen Separation Membranes Based on Dense Ceramic Conductors, in Inorganic Membranes: Synthesis, Characterization and Applications, Membrane Science and Technology Series, 13, R. Mallada and M. Menendez (Eds), Elsevier, 2008, Chapter 10, Pages 401-458.

[31] A. Julbe, D. Farrusseng, C. Guizard, Limitations and potentials of porous ceramic membranes for oxidation reactions, Catal. Today 104 (2005) 102-113. 
- [32] J. Garcia-Fayos, R. Ruhl, L. Navarrete, H.J.M. Bouwmeester, J.M. Serra, Enhancing oxygen permeation through $\mathrm{Fe}_{2} \mathrm{NiO}_{4}-\mathrm{Ce}_{0.8} \mathrm{~Tb}_{0.2} \mathrm{O}_{2}-\delta$ composite membranes using porous layers activated with $\mathrm{Pr}_{6} \mathrm{O}_{11}$ Nanoparticles, J. Mater. Chem. A 6 (2018) 1201-1209.

Example showing that a porous top-layer enhances the oxygen flux through dense membranes by increasing the specific surface area and number of active sites for oxygen exchange. This effect is further enhanced with addition of catalytic nanoparticles.

[33] F. Gallucci, J.A. Medrano, E. Fernandez, J. Melendez, M. van Sint Annaland, D.A. Pacheco-Tanaka, Advances on high temperature Pd-based membranes and membrane reactors for hydrogen purification and production. J. Membrane Sci. Res. 3 (2017) 142-156.

•• [34] S. B. Darling, Perspective: Interfacial materials at the interface of energy and water, J. Appl. Phys. 124 (2018) 030901.

A comprehensive paper focusing on understanding and controlling the interfaces between materials and water, thus evidencing the complexity of interface engineering for water treatment and the current energy-water challenges.

[35] A. Abdelrasoul, H. Doan, A. Lohi, Fouling in Membrane Filtration and Remediation Methods, Intech open, 2013, chapter 8 (DOI: 10.5772/52370).

$\bullet$ [36] X. Zhao, R. Zhang, Y. Liu, M. He, Y. Su, C. Gao, Z. Jiang, Antifouling membrane surface construction: Chemistry plays a critical role, J. Membrane Sci. 551 (2018) 145-171.

A review on the recent progress in antifouling membrane surface construction, with a focus on bioinspired adhesion, supramolecular chemistry, mineralization, click chemistry and coupling chemistry.

- [37] Hao-Cheng Yang, R. Z. Waldman, Ming-Bang Wu, J. Hou, L.Chen, S. B. Darling, Zhi-Kang Xu, Dopamine: Just the Right Medicine for Membranes, Adv. Funct. Mater. 28 (2018) 1705327

A review summarizing the substantial progress recently achieved in membrane surface engineering based on mussel-inspired coatings, and namely those derived from dopamine.

[38] C. Schlaich, Q. Wei, R. Haag, Mussel-Inspired Polyglycerol Coatings with Controlled Wettability: From Superhydrophilic to Superhydrophobic, Surface Coatings, Langmuir 2017, 33, 38, 9508-9520

[39] X. Liang, P. Wanga, J. Wang, Y. Zhang, W. Wu, J. Liua, B. van der Bruggen, Zwitterionic functionalized $\mathrm{MoS}_{2}$ nanosheets for a novel composite membrane with effective salt/dye separation performance, J. Membrane Sci. 573 (2019) 270-279.

[40] G. Mustafa, K. Wyns, A. Buekenhoudt, V. Meynen, New insights into the fouling mechanism of dissolved organic matter applying nanofiltration membranes with a variety of surface chemistries, Water Res. 93 (2016) 195-204.

[41] A. Al-Jumaili, S. Alancherry, D. Grant, A. Kumar, K. Bazaka, M. V. Jacob, Plasma Treatment of Polymeric Membranes, Non-Thermal Plasma Technology for Polymeric Materials- Applications in Composites, Nanostructured Materials and Biomedical Fields, Edited by S. Thomas, M. Mozetič, U. Cvelbar, P. Špatenka, 2019, Chapter 8, Pages 211-240.

$\bullet$ [42] M. Weber, A. Julbe, A. Ayral, P. Miele, M. Bechelany, Atomic Layer Deposition for Membranes: Basics, Challenges and Opportunities, Chem. Mater. 30 (2018) 7368-7390.

A review on the advances of ALD for the design of membrane top-layers with tailored composition, pore size, nanostructure and functionality, and thus good control over surface/fluid interactions.

- [43] H.C. Yang, R.Z. Waldman, Z. Chen, S.B. Darling, Atomic layer deposition for membrane interface engineering, Nanoscale 10 (2018) 20505-20513.

A review that illustrates the application of ALD and related techniques for the design of novel membrane interfaces. 
[44] H.C. Yang, Y. Xie, H. Chan, B. Narayanan, L. Chen, R.Z. Waldman, S.K.R.S. Sankaranarayanan, J.W. Elam, S.B. Darling, Crude-Oil-Repellent Membranes by Atomic Layer Deposition: Oxide Interface Engineering, ACS Nano. 12 (2018) 8678-8685.

[45] M. Kadhom, W. Hu, B. Deng, Metal-organic frameworks (MOFs) in water filtration membranes for desalination and other applications, Appl. Mater. Today 11 (2018) 219-230.

- [46] X. Li, Y. Liu, J. Wang, J. Gascon, J. Li, B. van der Bruggen, Metal-organic frameworks based membranes for liquid separation, Chem. Soc. Rev. 46 (2017) 7124-7144.

A tutorial overview and outlook for MOF-based membranes for liquid separations such as pervaporation, water treatment, and organic solvent nanofiltration.

[47] M. Weber, B. Koonkaew, S. Balme, I. Utke, F. Picaud, I. latsunskyi, E. Coy, P. Miele, M. Bechelany, Boron Nitride Nanoporous Membranes with High Surface Charge by Atomic Layer Deposition, ACS Appl. Mater. Interfaces 9 (2017) 16669-16678.

[48] C. Chen, J. Wang, D. Liu, C.Yang, Y. Liu, R.S. Ruoff, W. Lei, Functionalized boron nitride membranes with ultrafast solvent transport performance for molecular separation, Nat. Commun. 9 (2018) 1902.

[49] D. González, J. Amigo, F. Suárez, Membrane distillation: perspectives for sustainable and improved desalination, Sustain. Energy Rev. 80 (2017) 238-259.

[50] R.S.K. Madsen, J. Motuzas, J. Vaughan, A. Julbe, J.C. Diniz da Costa, Fine Control of NaCl Crystal Size and Particle Size in Percrystallisation by Tuning the Morphology of Carbonised Sucrose Membranes, J. Membrane Sci. 567 (2018) 157-165.

•• [51] J. Zhu, J. Hou, A. Uliana, Y. Zhang, M. Tian, B. van der Bruggen, The rapid emergence of two-dimensional nanomaterials for high-performance separation membranes, J. Mater. Chem. A 6 (2018) 3773-3792.

A review on the use of various 2D materials for membrane designs. Some remarkable performances of these membranes and their separation mechanisms are underlined.

[52] R.K. Joshi, P. Carbone, F.C. Wang, V.G. Kravets, Y. Su, I.V. Grigorieva, H.A. Wu, A.K. Geim, R.R. Nair, Precise and ultrafast molecular sieving through graphene oxide membranes, Science 343 (2014) 752-754.

$\bullet$ [53] Q. Yang, Y. Su, C. Chi, C.T. Cherian, K. Huang, V.G. Kravets, F.C. Wang, J.C. Zhang, A. Pratt, A.N. Grigorenko, F. Guinea, A.K. Geim, R.R. Nair, Ultrathin graphene-based membrane with precise molecular sieving and ultrafast solvent permeation, Nat. Mater. 16 (2017) 1198-1202.

A demonstration of the potential of ultrathin GO laminates ( $10 \mathrm{~nm})$ for organic solvent nanofiltration (>99.9\% rejection of small molecular weight organic dyes dissolved in methanol).

[54] S. Roy, N.R. Singha, Polymeric Nanocomposite Membranes for Next Generation Pervaporation Process: Strategies, Challenges and Future Prospects, Membranes 7(2017) 53.

[55] V. Vatanpour, M. Safarpour, A. Khataee, Mixed Matrix Membranes for Nanofiltration Application, in Nanostructured Polymer Membranes: Applications, P.M. Visakh, O. Nazarenko Eds, Wiley, 2016; Separation \& Purification Reviews Volume 46.

- [56] Y. Cai, D. Chen, N. Li, Q. Xu, H. Li, Nanofibrous metal-organic framework composite membrane for selective efficient oil/water emulsion separation, J. Membrane Sci. 543 (2017) 10-17.

First example of prewetting-induced superhydrophobic or superoleophobic behavior of membranes (nanofibrous PAN@ZIF-8) used to separate oil-in-water or water-in-oil emulsions.

[57] X. Zhang, S. Yang, B. Yu, Q. Tan, X. Zhang, H. Cong, Advanced Modified Polyacrylonitrile Membrane with Enhanced Adsorption Property for Heavy Metal Ions, Sci. Rep. 8 (2018) 1260. 
[58] J.E. Efome, D. Rana, T. Matsuura, C.Q. Lan, Insight Studies on Metal-Organic Framework Nanofibrous Membrane Adsorption and Activation for Heavy Metal lons Removal from Aqueous Solution, ACS Appl. Mater. Interfaces 10 (2018) 18619-18629.

[59] M. Taheran, M. Naghdi, S.K. Brar, E. Knystautas, M. Verma, R.Y. Surampalli, J.R. Valero, Development of adsorptive membranes by confinement of activated biochar into electrospun nanofibers, J. Nanotechnol. 7 (2016) 1556-1563.

[60] D. Sun, M. Meng, Y. Lu, B. Hu, Y. Yan, C. Li, Porous nanocomposite membranes based on functional GO with selective function for lithium adsorption, New J. Chem. 42 (2018) 4432-4442.

[61] M.S. Atab, A.J. Smallbone, A.P. Roskilly, A hybrid reverse osmosis/adsorption desalination plant for irrigation and drinking water, Desalination 444 (2018) 44-52.

- [62] Y. Liao, S. Goh, M. Tian, R. Wanga, A. G.Fane, Design, development and evaluation of nanofibrous composite membranes with opposing membrane wetting properties for extractive membrane bioreactors, J. Membrane Sci. 551 (2018) 55-65.

An example of Janus-type membrane with superhydrophobic and superhydrophilic surfaces offering competitive performance in cross-flow and submerged extractive membrane bioreactors.

[63] V. Rouessac, A. van der Lee, F. Bosc, J. Durand, A. Ayral, Three characterization techniques coupled with adsorption for studying the nanoporosity of supported films and membranes, Micro. Meso. Mater. 111 (2008) 417-428.

[64] E.I. Shkolnikov, E.V. Sidorova, A.O. Malakhov, V.V. Volkov, A. Julbe, A. Ayral, Estimation of pore size distribution in MCM-41-type silica using a simple desorption technique, Adsorption 17 (2011) 911-918.

[65] F. Zamani, E. Akhondi, K. Ebrahim, K. Geert-Henk, B. William, A.G. Fane, J.W. Chew, Evapoporometry adaptation to determine the lumen-side pore-size distribution (PSD) of hollow fiber and tubular membranes, J. Membrane Sci. 526 (2017) 1-8.

[66] H. Kita, Zeolite membranes for pervaporation, in Advanced Materials for Membrane Fabrication and Modification, Stephen Gray, Toshinori Tsuru, Yoram Cohen and Woei-Jye Lau Eds, CRC Press, 2018, Chapter 12.

[67] M. Lépinay, L. Broussous, C. Licitra, F. Bertin, V. Rouessac, A. Ayral, B. Coasne, Probing the microporosity of low-k organosilica films: MP and t-plot methods applied to ellipsometric porosimetry data, Micro. Meso. Mater. 217 (2015) 119-124.

[68] M. Yu, J.L. Falconer, R.D. Noble, Characterizing Nonzeolitic Pores in MFI Membranes, Ind. Eng. Chem. Res., 47 (2008) 3943-3948.

[69] I. Kumakiri, M. Stange, T.A. Peters, H. Klette, H. Kita, R. Bredesen, Defect detection by permeation mapping, Micropor. Mesopor. Mat. 115 (2008) 33-39. 